\title{
IN SILICO IDENTIFICATION OF NOVEL DRUG TARGETS IN ACINETOBACTER BAUMANNII BY SUBTRACTIVE GENOMIC APPROACH
}

\author{
MEENU GOYAL ${ }^{1}$, CITU $^{1}$, NIDHI SINGH ${ }^{2 *}$ \\ ${ }^{1}$ Department of Biotechnology, Central University of Haryana, Mahendergarh, Haryana, India. ${ }^{2}$ Molecular and Structural Biology Division, \\ CSIR - Central Drug Research Institute, Lucknow, Uttar Pradesh, India. Email: tanwar.nidhi7@gmail.com
}

Received: 19 July 2017, Revised and Accepted: 18 August 2017

\section{ABSTRACT}

Objective: Multiple drug resistance (MDR) in bacteria, particularly Gram-negative bacilli, has significantly hindered the treatment of infections caused by these bacteria. This results in the need for identifying new drugs and drug targets for these bacteria. The objective of this study was to identify novel drug targets in Acinetobacter baumannii which has emerged as a medically important pathogen due to an increasing number of infections caused by it and its MDR property.

Methods: In our study, we implemented in silico subtractive genomics approach to identify novel drug targets in A. baumannii American type culture collection 17978. Various databases and online software were used to build a systematic workflow involving comparative genomics, metabolic pathways analysis, and drug target prioritization to identify pathogen-specific novel drug targets.

Results: First, 458 essential proteins were retrieved from a database of essential genes, and by performing BLASTp against Homo sapiens, 246 human non-homologous essential proteins were selected of 458 proteins. Metabolic pathway analysis performed by Kyoto Encyclopedia of Genes and Genomes-Kyoto Automatic Annotation Server revealed that these 246 essential non-homologous proteins were involved in 66 metabolic pathways. Among these metabolic pathways, 12 pathways were found to be unique to Acinetobacter that involved 37 non-homologous essential proteins. Of these essential non-homologous proteins, 19 proteins were found in common as well as unique metabolic pathways and only 18 proteins were unique to Acinetobacter. Finally, these target proteins were filtered to 9 potential targets, based on subcellular localization and assessment of druggability using Drug bank, ChEMBL, and literature.

Conclusion: Our study identified nine potential drug targets which are novel targets in A. baumannii and can be used for designing drugs against these proteins. These drugs will be pathogen specific with no side effects on human host, as the potential drug targets are human non-homologous.

Keywords: Acinetobacter baumannii, Multiple drug resistance, Essential proteins, Metabolic pathway analysis, Druggability, Novel drug target.

(C) 2018 The Authors. Published by Innovare Academic Sciences Pvt Ltd. This is an open access article under the CC BY license (http://creativecommons. org/licenses/by/4. 0/) DOI: http://dx.doi.org/10.22159/ajpcr.2018.v11i3.22105

\section{INTRODUCTION}

Some strains of bacteria are resistant to almost all available antibiotics, such as Acinetobacter baumannii, which is the focus of the present study. Antimicrobial resistance has been identified as one of the most important problems facing human health [1]. The most common and serious multiple drug-resistant (MDR) pathogens have been assigned within the acronym "ESKAPE," standing for Enterococcus faecium, Staphylococcus aureus, Klebsiella pneumoniae, A. baumannii, Pseudomonas aeruginosa, and Enterobacter spp. [2]. Treatment of infections due to these bacteria has become difficult, resulting in increased morbidity and mortality [3,4]. A. baumannii is one of these most problematic MDR species [5]. Therefore, the identification of new drug targets in A. baumannii is urgently needed.

A. baumannii is a Gram-negative bacillus that is aerobic, pleomorphic, and non-motile. It is an opportunistic pathogen which mainly affects immunocompromised individuals, particularly those who have experienced a prolonged ( $>90$ day) hospital stay [6]. The respiratory tract, blood, pleural fluid, urinary tract, surgical wounds, central nervous system, skin, and eyes are sites for infection or colonization $[7,8]$. The types of infections caused by this pathogen include pneumonia, bacteremia, endocarditis, skin and soft tissue infections, urinary tract infections, and meningitis.

OmpA, a member of the outer membrane proteins (OMPs), contributes significantly to the disease-causing potential of $A$. baumannii [9]. OmpA, being the most abundant surface protein on the pathogen, is also involved in the formation of biofilms [10,11]. The ability to form biofilms allows it to grow persistently in unfavorable conditions and environments. Phospholipase $\mathrm{D}$ and $\mathrm{C}$ also contribute to virulence potential of A. baumannii [12,13].

A. baumannii is able to acquire antibiotic resistance mechanisms which allow this organism to persist in hospital environments and facilitated the global emergence of MDR strains. The rapid emergence of multi- and pandrug-resistant strains of Acinetobacter highlights the organism's ability to quickly acclimatize to selective changes in environmental pressures. The three fundamental mechanisms of antimicrobial resistance are (1) enzymatic degradation of antibacterial drugs, (2) alteration of bacterial proteins that are antimicrobial targets, and (3) changes in membrane permeability to antibiotics. In recent years, it has been designated as a "red alert" human pathogen, arising largely from its extensive antibiotic resistance spectrum [14].

In the present post-genomics era, the possibilities of selecting targets using computational approaches with integrated "omics" data, such as genomics, proteomics, and metabolomics have been increasing continuously. In silico methods like comparative and subtractive genomics are being widely used for the prediction and identification of potential drug targets in numerous pathogenic bacteria [15]. This technique relies on comparisons between the genomic sequences of the pathogen with the host to include the protein-coding genes sequences that are (a) absent in the host (non-homologous) and (b) indispensable for pathogen survival $[16,17]$. In the present study, a computational 
comparative metabolic pathway analysis of host Homo sapiens and A. baumannii has been carried out to identify potential novel drug targets.

\section{METHODS}

The systematic identification and characterization of the potential drug targets of A. baumannii American type culture collection 17978 was done sequentially by the following methods.

\section{Retrieval of essential proteins of $A$. baumannii}

At first, according to the database of essential genes (DEG) [18], 458 essential proteins of $A$. baumannii were retrieved from NCBI in FASTA format.

Identification of non-human homologous essential proteins in A. baumannii

To identify human non-homologous essential proteins of A. baumannii, these 458 essential proteins were subjected to BlastP at NCBI server against $H$. sapiens with default parameters. Proteins having identity $\leq 38 \%$ and e $>0.005$ were considered as nonhomologous proteins.

\section{Metabolic pathway analysis}

The human non-homologous essential proteins of $A$. baumannii obtained through BlastP were then subjected to metabolic pathway analysis, which was done by Kyoto Automatic Annotation Server (Kyoto Encyclopedia of Genes and Genomes [KEGG] automatic annotation server) [19] server at KEGG [20].

\section{Unique pathway identification}

After this, unique metabolic pathways of Acinetobacter were identified through the manual comparison of metabolic pathways of both Acinetobacter and H. sapiens using KEGG Database.

\section{Subcellular localization}

Subcellular localization of metabolic proteins (essential non-human homologous protein involved only in unique pathways) of $A$. baumannii was done by PSORTb [21] to identify the cellular localization of these putative therapeutic targets.

\section{Drug target prioritization}

Drug targets were prioritized by following three approaches:

\section{Drug bank}

Druggability of potential drug targets of $A$. baumannii was identified by sequence similarity to targets of the Food and Drug Administration (FDA) approved and small drug molecule by utilizing the Drug Bank [22].

\section{ChEMBL}

Druggability of potential drug targets of A. baumannii was identified by sequence similarity to targets of small drug molecule by utilizing the ChEMBL [23]. The default parameters for BLASTp were used to line up the potential drug targets from A. baumannii against the list of protein targets of compounds found within the Drug Bank and ChEMBL.

\section{LITERATURE}

Druggability of potential drug targets was also assessed based on information in the literature [24-32] about their efficacy as drug targets in other organisms.

\section{RESULTS AND DISCUSSION}

The present study was aimed to identify novel drug targets in A. baumannii. We followed subtractive genomic approach (Fig. 1) to identify the good therapeutic target proteins which are essential for bacterial survival but cannot be found in the host.

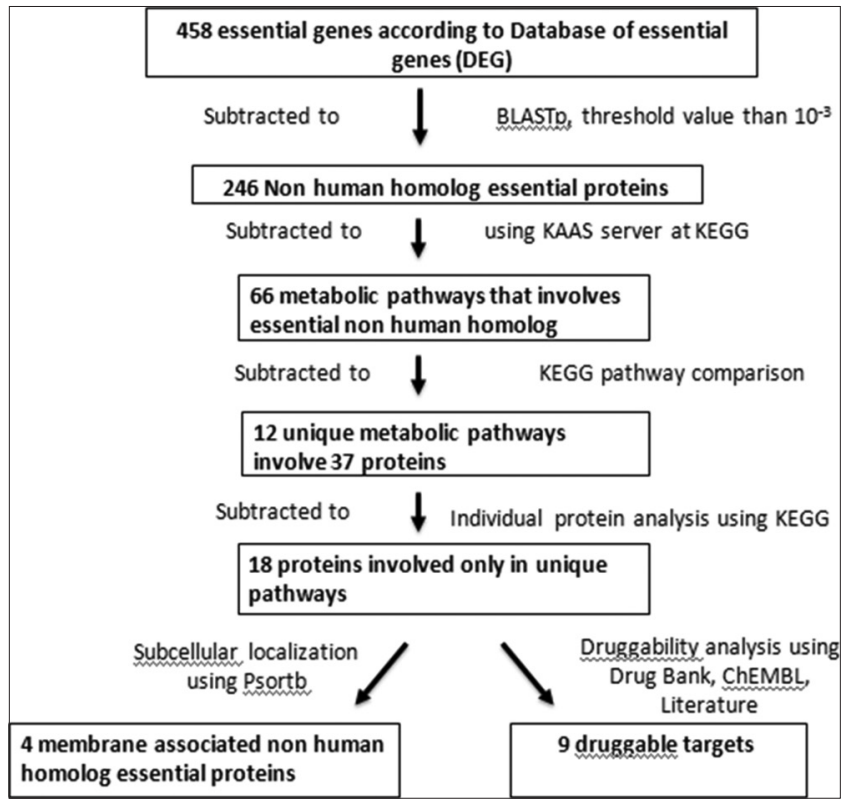

Fig. 1: A schematic representation of identification of novel drug targets in Acinetobacter baumannii

Identification of non-homologous essential proteins

At first, essential proteins of A. baumanni were retrieved from DEG database. To avoid any cross-reactivity of established drug with human host, 458 essential proteins were subjected to BLASTp against H. sapiens. Based on the result of BLASTp, 246 non-human homologous proteins were selected having identity $\leq 38 \%$ and e value cutoff $>0.005$.

Identification of essential non-homologous proteins involved in unique metabolic pathways

Metabolic pathway analysis of these 246 non-homologous proteins showed the involvement of these proteins in 66 pathways. Pathway comparison of A. baumannii and $H$. sapiens revealed 12 metabolic pathways that were unique to $A$. baumannii, and rest 54 pathways were common in pathogen and host. These 12 pathways involved 37 essential non-homologous proteins of $A$. baumannii.

These 37 essential non-homologous proteins were individually studied using KEGG database (Table 1). Of these 37 proteins, 18 proteins were found to be involved exclusively in unique metabolic pathways, while rest 19 proteins were involved in multiple unique pathways as well as in some common pathways between $H$. sapiens and A. baumannii. These 19 proteins were playing role in multiple pathways. Along with the involvement in unique pathways in unique pathways of pathogen, these 19 proteins were also involved in some pathways common between pathogen and host. Therefore, these were not considered for further analysis.

\section{Subcellular localization}

Until now, we have discussed about non-homologous essential proteins of the pathogen using computational comparative and subtractive genomics study. Although this is the major criterion in determining drug target from a pathogen, several other factors are taken into consideration for suitability of drug and vaccine targets. In silico prediction of subcellular localization provides a quick and inexpensive means for obtaining information regarding protein function. Cytoplasmic or membrane localization of the targets determines the ease of purification steps to be followed in experimental studies. In our study, of 18 essential protein targets, 4 are membrane proteins and rest fall into the category of cytoplasmic proteins, as predicted by PSORTb (Table 2).

Druggability of putative therapeutic targets

Druggability of each of the non-homologous essential proteins of A. baumannii was identified by sequence similarity to targets of 
Table 1: Essential non-homologous proteins involved in 12 unique metabolic pathways

\begin{tabular}{|c|c|c|c|}
\hline \multicolumn{2}{|c|}{ Essential non-homologous proteins } & \multicolumn{2}{|l|}{ Involvement in pathways } \\
\hline KO entry & Definition & Unique pathway & Common pathway \\
\hline K01623 & Fructose-bisphosphate aldolase, Class I & ko00680-Methane metabolism & $\begin{array}{l}\text { ko00010-Glycolysis/gluconeogenesis } \\
\text { ko00030-Pentose phosphate pathway } \\
\text { ko00051-Fructose and mannose } \\
\text { metabolism } \\
\text { ko00710-Carbon fixation in } \\
\text { photosynthetic organisms } \\
\text { ko01200-Carbon metabolism } \\
\text { ko1230-Biosynthesis of amino acids }\end{array}$ \\
\hline K15633 & $\begin{array}{l}\text { 2,3-Bisphosphoglycerate-independent } \\
\text { phosphoglycerate mutase }\end{array}$ & ko00680-Methane metabolism & $\begin{array}{l}\text { ko00010-Glycolysis/gluconeogenesis } \\
\text { ko1230-Biosynthesis of amino acids } \\
\text { ko00260-Glycine, serine, and } \\
\text { threonine metabolism } \\
\text { ko01200-Carbon metabolism }\end{array}$ \\
\hline K01007 & Pyruvate, water dikinase & ko00680-Methane metabolism & $\begin{array}{l}\text { ko00620-Pyruvate metabolism } \\
\text { ko00720-Carbon fixation pathway in } \\
\text { prokaryotes } \\
\text { ko01200-Carbon metabolism }\end{array}$ \\
\hline K00677 & UDP-N-acetylglucosamine acyltransferase & $\begin{array}{l}\text { ko00540-Lipopolysaccharide } \\
\text { biosynthesis } \\
\text { ko01503-(cAMP) resistance }\end{array}$ & \\
\hline K02535 & $\begin{array}{l}\text { UDP-3-0-[3-hydroxymyristoyl] N-acetylglucosamine } \\
\text { deacetylase }\end{array}$ & $\begin{array}{l}\text { ko00540-Lipopolysaccharide } \\
\text { biosynthesis }\end{array}$ & \\
\hline K02536 & $\begin{array}{l}\text { UDP-3-0-[3-hydroxymyristoyl] glucosamine } \\
\text { N-acyltransferase }\end{array}$ & $\begin{array}{l}\text { ko00540-Lipopolysaccharide } \\
\text { biosynthesis }\end{array}$ & \\
\hline K03269 & UDP-2,3-diacylglucosamine hydrolase & $\begin{array}{l}\text { ko00540-Lipopolysaccharide } \\
\text { biosynthesis }\end{array}$ & \\
\hline K00748 & Lipid-A-disaccharide synthase & $\begin{array}{l}\text { ko00540-Lipopolysaccharide } \\
\text { biosynthesis }\end{array}$ & \\
\hline K00912 & Tetraacyldisaccharide 4'-kinase & $\begin{array}{l}\text { ko00540-Lipopolysaccharide } \\
\text { biosynthesis }\end{array}$ & \\
\hline K02527 & 3-Deoxy-D-manno-octulosonic-acid transferase & $\begin{array}{l}\text { ko00540-Lipopolysaccharide } \\
\text { biosynthesis }\end{array}$ & \\
\hline K03270 & $\begin{array}{l}\text { 3-Deoxy-D-manno-octulosonate 8-phosphate } \\
\text { phosphatase }\end{array}$ & $\begin{array}{l}\text { ko00540-Lipopolysaccharide } \\
\text { biosynthesis }\end{array}$ & \\
\hline K06041 & Arabinose-5-phosphate isomerase & $\begin{array}{l}\text { ko00540-Lipopolysaccharide } \\
\text { biosynthesis }\end{array}$ & \\
\hline K01921 & D-alanine-D-alanine ligase & $\begin{array}{l}\text { ko00550-Peptidoglycan } \\
\text { synthesis } \\
\text { ko01502-Vancomycin resistance } \\
\text { ko00473-D-alanine metabolism }\end{array}$ & \\
\hline K00790 & UDP-N-acetylglucosamine 1-carboxyvinyltransferase & $\begin{array}{l}\text { ko00550-Peptidoglycan } \\
\text { synthesis }\end{array}$ & $\begin{array}{l}\text { ko00520-Amino sugar and nucleotide } \\
\text { sugar metabolism }\end{array}$ \\
\hline K00075 & UDP-N-acetylmuramate dehydrogenase & $\begin{array}{l}\text { ko00550-Peptidoglycan } \\
\text { synthesis }\end{array}$ & $\begin{array}{l}\text { ko00520-Amino sugar and nucleotide } \\
\text { sugar metabolism }\end{array}$ \\
\hline K01924 & UDP-N-acetylmuramate--alanine ligase & $\begin{array}{l}\text { ko00550-Peptidoglycan } \\
\text { synthesis }\end{array}$ & $\begin{array}{l}\text { ko00471-D glutamine and D } \\
\text { glutamate metabolism }\end{array}$ \\
\hline K01925 & UDP-N-acetylmuramoylalanine--D-glutamate ligase & $\begin{array}{l}\text { ko00550-Peptidoglycan } \\
\text { synthesis }\end{array}$ & $\begin{array}{l}\text { ko00471-D glutamine and D } \\
\text { glutamate metabolism }\end{array}$ \\
\hline K01928 & $\begin{array}{l}\text { UDP-N-acetylmuramoyl-L-alanyl- } \\
\text { D-glutamate--2,6-diaminopimelate ligase }\end{array}$ & $\begin{array}{l}\text { ko00550-Peptidoglycan } \\
\text { synthesis }\end{array}$ & ko00300-Lysine biosynthesis \\
\hline K01929 & $\begin{array}{l}\text { UDP-N-acetylmuramoyl-tripeptide- } \\
\text {-D-alanyl-D-alanine ligase }\end{array}$ & $\begin{array}{l}\text { ko00550-Peptidoglycan } \\
\text { synthesis } \\
\text { ko01502-Vancomycin resistance }\end{array}$ & ko00300-Lysine biosynthesis \\
\hline K01000 & Phospho-N-acetylmuramoyl-pentapeptide-transferase & $\begin{array}{l}\text { ko00550-Peptidoglycan } \\
\text { synthesis } \\
\text { ko01502-Vancomycin resistance }\end{array}$ & \\
\hline K02563 & $\begin{array}{l}\text { UDP-N-acetylglucosamine- } \\
\text {-N-acetylmuramyl-(pentapeptide) } \\
\text { pyrophosphoryl-undecaprenol N-acetylglucosamine } \\
\text { transferase }\end{array}$ & $\begin{array}{l}\text { ko00550-Peptidoglycan } \\
\text { synthesis } \\
\text { ko01502-Vancomycin resistance }\end{array}$ & \\
\hline K03980 & Putative peptidoglycan Lipid II flippase & $\begin{array}{l}\text { ko00550-Peptidoglycan } \\
\text { synthesis }\end{array}$ & \\
\hline
\end{tabular}


Table 1: (Continued)

\begin{tabular}{ll}
\hline \multicolumn{2}{l}{ Essential non-homologous proteins } \\
\hline K03587 & Cell division protein Ftsz \\
& \\
K13779 & Isohexenylglutaconyl-CoA hydratase \\
K00928 & Aspartate kinase
\end{tabular}

K00133 Aspartate-semialdehyde dehydrogenase

K00215 4-Hydroxy-tetrahydrodipicolinate reductase

K03072 Preprotein translocase subunit SecD

K03076 Preprotein translocase subunit SecY

K03073 Preprotein translocase subunit SecE

K03210 Preprotein translocase subunit YajC

K03217 YidC/Oxa1 family membrane protein insertase

K07659 Two-component system, OmpR family, phosphate regulon response regulator $0 \mathrm{mpR}$

K07638 Two-component system, OmpR family, osmolarity sensor histidine kinase EnvZ

K01497 GTP Cyclohydrolase II

K03100 Signal peptidase I
Involvement in pathways

ko00550-Peptidoglycan

synthesis

ko01501-Beta-lactam resistance

ko00281-Geraniol degradation

ko00261-Monobactam

biosynthesis

ko00261-Monobactam

biosynthesis

ko00261-Monobactam

biosynthesis

ko03070-Bacterial secretion

system

ko03070-Bacterial secretion

system

ko02024-Quorum sensing

ko03070-Bacterial secretion

system

ko02024-Quorum sensing

ko03070-Bacterial secretion

system

ko02024-Quorum sensing

ko03070-Bacterial secretion

system

ko02024-Quorum sensing

ko02020-Two-component

system

ko02020-Two-component

system

ko02024-Quorum sensing

ko02024-Quorum sensing ko001210-2-0xocarboxylic acid

metabolism

ko00300-Lysine biosynthesis

ko1230-Biosynthesis of amino acids

ko00260-Glycine, serine and

threonine metabolism

ko00270-Cysteine and methionine

metabolism

ko001210-2-0xocarboxylic acid

metabolism

ko00300-Lysine biosynthesis

ko1230-Biosynthesis of amino acids

ko00260-Glycine, serine and

threonine metabolism

ko00270-Cysteine and methionine

metabolism

ko00300-Lysine biosynthesis

ko1230-Biosynthesis of amino acids

ko03060-Protein export

ko03060-Protein export

ko03060-Protein export

ko03060-Protein export

ko03060-Protein export

ko00740-Riboflavin metabolism ko03060-Protein export

GTP: Guanosine triphosphate, cAMP: Cationic antimicrobial peptide

Table 2: Subcellular localization of proteins that are involved in only unique metabolic pathways

\begin{tabular}{llll}
\hline $\begin{array}{l}\text { KO } \\
\text { entry }\end{array}$ & DEG No. & $\begin{array}{l}\text { Subcellular } \\
\text { localization }\end{array}$ & $\begin{array}{l}\text { Whether } \\
\text { druggable }\end{array}$ \\
\hline K01921 & DEG10430441 & Cytoplasmic & Yes \\
K00677 & DEG10430227 & Cytoplasmic & No \\
K02535 & DEG10430437 & Cytoplasmic & Yes \\
K02536 & DEG10430230 & Cytoplasmic & No \\
K00748 & DEG10430208 & Cytoplasmic & No \\
K00912 & DEG10430193 & Cytoplasmic & No \\
K02527 & DEG10430432 & Cytoplasmic & No \\
K00979 & DEG10430194 & Cytoplasmic & No \\
K03270 & DEG10430173 & Cytoplasmic & No \\
K06041 & DEG10430172 & Cytoplasmic & Yes \\
K03269 & DEG10430248 & Cytoplasmic & No \\
K01000 & DEG10430418 & Inner membrane & Yes \\
K02563 & DEG10430443 & Inner membrane & Yes \\
K03980 & DEG10430010 & Inner membrane & No \\
K03587 & DEG10430438 & Cytoplasmic & Yes \\
K13779 & DEG10430368 & Cytoplasmic & Yes \\
K07638 & DEG10430428 & Inner membrane & Yes \\
K07659 & DEG10430427 & Cytoplasmic & Yes \\
\hline
\end{tabular}

small molecule drugs by utilizing the Drug Bank database, ChEMBL, literature. This led to the identification of nine A. baumannii proteins that were highly similar to the binding partners of FDA approved and small experimental molecule drugs (Table 3), and these can act as potential novel drug targets.

The above listed nine potential druggable targets are involved in seven metabolic pathways (two-component system, D-alanine metabolism, lipopolysaccharide biosynthesis, geraniol degradation, beta-lactam resistance, vancomycin resistance, and peptidoglycan synthesis pathways) and their potential as novel drug targets is discussed as follows:

\section{D-alanine ligase}

D-alanine ligase is involved in 3 bacterial pathways, i.e., peptidoglycan synthesis, D-alanine metabolism, and vancomycin resistance. Due to involvement in multiple pathways, it is a very good target for drug discovery. This enzyme is ubiquitous among prokaryotes and is absent in eukaryotes making this a logical target for the development of antibiotics. This enzyme has been used as target for many drugs against infectious bacteria. Bruning et al. have used this enzyme as target for drug D-cycloserine in Mycobacterium tuberculosis [24]. 
Table 3: Proteins highly similar to the targets of FDA approved and small experimental molecule drugs

\begin{tabular}{|c|c|c|c|c|}
\hline DEG Number & KO entry & Drug & Organism & Source \\
\hline \multirow{3}{*}{ DEG10430441 } & K01921 & d-Cycloserine & M. tuberculosis & Bruning et al. [24] \\
\hline & & Diazenedi carboxamides phosphinic acid & E. coli & Kovac et al. [25] \\
\hline & & Aminoethylphosphonic acid & P. aeruginosa, S. faecalis & Lacoste et al. [26] \\
\hline DEG10430172 & K06041 & 4-Phosphoerythronic acid & - & Woodruff and Wolfenden [27] \\
\hline \multirow{2}{*}{ DEG10430418 } & K01000 & Amphomycin Mureidomycin A & B. megaterium & Tanaka et al. [28] \\
\hline & & Tunicamycin Liposidomycin B & E. coli & Brandish et al. [29] \\
\hline \multirow[t]{2}{*}{ DEG10430438 } & K03587 & $\begin{array}{l}\text { 5'-Guanosine-diphosphate-monothiophosphate and } \\
\text { citric acid }\end{array}$ & - & Drug bank \\
\hline & & - & P. aeruginosa & ChEMBL \\
\hline \multirow[t]{2}{*}{ DEG10430428 } & K07638 & Thienopyridine & - & Gilmour et al. [30] \\
\hline & & Radicicol & - & Drug bank \\
\hline \multirow[t]{2}{*}{ DEG10430437 } & K02535 & DPA & - & Zhang et al. [31] \\
\hline & & Ethylenediaminetetraacetic acid & - & Jackman et al. [32] \\
\hline \multirow[t]{2}{*}{ DEG10430427 } & K07659 & - & A. platensis & ChEMBL \\
\hline & & Glycerol & - & Drug bank \\
\hline DEG10430443 & K02563 & - & E. coli & ChEMBL \\
\hline DEG10430368 & K13779 & Quercetin & - & Drug bank \\
\hline
\end{tabular}

FDA: Food and drug administration, DPA: Dipicolinic acid, M. tuberculosis: Mycobacterium tuberculosis, E. coli: Escherichia coli, P. aeruginosa: Pseudomonas aeruginosa, S. faecalis: Streptococcus faecalis, B. megaterium: Bacillus megaterium, A. platensis: Arthrospira platensis

This enzyme has also been used as drug target by other researchers $[25,26,33,34]$.

\section{Osmolarity sensor histidine kinase EnvZ and phosphate regulon response regulator}

These proteins are involved in two-component system and belong to OmpR family. Two-component regulatory systems enable bacteria to detect physical or chemical changes and are mediators of signal transduction. This pathway is essential for the survival of bacteria and any disruption in this pathway leads to bacterial cell death. Twocomponent system pathway has been targeted by many inhibitors in different bacteria [35-40], and therefore, it can be very potent drug target in Acinetobacter too.

\section{Cell division protein FtsZ}

This protein is involved in 2 important metabolic pathways of A. baumannii, namely, peptidoglycan synthesis and beta-lactam resistance pathways. Beta-lactam resistance pathway codes for betalactamase which plays role in degradation of beta-lactam antibiotics and makes them inactive. Drugs targeting this protein can inactivate beta-lactam resistance pathway and hence making the pathogen sensitive to beta-lactam antibiotics. Furthremore, disruption of peptidoglycan synthesis leads to bacterial cell death. Hence, this protein is an effective drug target as it is involved in two crucial pathways of the bacterial pathogen. This is supported by many wet laboratory studies where drugs have been used against FtsZ [41-46]. Sun et al. [47] used berberine-based FtsZ inhibitors with broadspectrum antibacterial activity.

\section{Arabinose-5-phosphate isomerase and UDP-3-0-[3- hydroxymyristoyl]- $\mathrm{N}$-acetylglucosamine deacetylase}

These proteins are involved in lipopolysaccharide synthesis. Lipopolysaccharides (e.g., lipid A) are essential constituents of bacterial endotoxin. Chemical inhibitors which can disrupt lipid A biosynthesis have the potential to act as antimicrobial agents. Lipid A biosynthesis occurs on the cytosolic surface of the inner membrane and is catalyzed by 10 unique enzymes. Arabinose-5-phosphate isomerase catalyzes first step in the synthesis of lipopolysaccharide and has been used as a drug target in many pathogens [27,48-50]. UDP-3-0-[3-hydroxymyristoyl] N-acetylglucosamine deacetylase catalyzes the hydrolysis of UDP-3-0-myristoyl- $\mathrm{N}$-acetylglucosamine to form UDP-3-0-myristoylglucosamine and acetate, the committed step in lipid A biosynthesis, and has been exploited as a drug target by various workers [31,32]. Inhibition of lipopolysaccharide biosynthesis, leading to a truncated lipopolysaccharide molecule, is a strategy for antibacterial drug development in which vital cellular structure is weakened [51].
UDP-N-acetylglucosamine- $\mathrm{N}$-acetylmuramyl-(pentapeptide) pyrophosphoryl-undecaprenol $\mathrm{N}$-acetylglucosamine transferase (MurG) and phospho-N-acetylmuramoyl-pentapeptidetransferase (MraY)

These proteins are involved in peptidoglycan synthesis and vancomycin resistance pathways. The bacterial cell is surrounded by layers of peptidoglycan, a covalently cross-linked polymer matrix composed of peptide-linked $\beta$-(1-4)-N-acetyl hexosamine. Peptidoglycan provides mechanical strength to bacteria helping it to survive under varying osmotic pressures. The proteins such as MurG and MraY, involved in peptidoglycan synthesis, can be good targets of inhibitors against bacteria and their role as drug targets has also been reported in previous studies on other organisms [52-55].

The potential drug targets identified in this study have been successfully used as drug targets in other pathogens and hence have the potential to be exploited for designing new antimicrobial agents against A. baumannii. Computer-aided drug design approach can further be used to identify hit and lead compounds against these targets [56].

\section{CONCLUSION}

As resistant to all available antibiotics is reported in most of Gram-negative bacteria, especially in A. baumannii. Hence, there is a need to develop antibiotics against new drug targets. Our study found nine potential druggable proteins that are novel drug targets in $A$. baumannii and can be used for designing drugs against them. All of these have the potential to be used as drug targets as these are involved in crucial metabolic pathways of the pathogen and have been targeted successfully in other organisms. The drug would be specific for the pathogen and would not be lethal to the host as subtractive genomic approach applied in this case which includes human non-homologous proteins only. Molecular modeling of the targets will help in drug discovery by in silico methods. Virtual screening against these novel drug targets might be useful in the discovery of potential therapeutic agents against $A$. baumannii and can help in dealing with MDR.

\section{ACKNOWLEDGMENT}

Facilities provided by the Department of Biotechnology, Central University of Haryana are gratefully acknowledged.

\section{AUTHOR CONTRIBUTIONS}

Meenu Goyal designed the overall methodology, revised manuscript and supervised the carried out work. Citu carried out the work and helped in preparing the first draft of manuscript. Nidhi Singh assisted in designing methodology, conducting data analysis and participated in critically reviewing the manuscript. 


\section{CONFLICT OF INTERESTS}

The authors declare no conflicts of interest in this work.

\section{REFERENCES}

1. Arora D, Jindal N, Romit KR. Emerging antibiotic resistance in Pseudomonas aeruginosa. Int J Pharm Pharm Sci 2011;3:82-4.

2. Rice LB. Federal funding for the study of antimicrobial resistance in nosocomial pathogens: No ESKAPE. J Infect Dis 2008;197:1079-81.

3. Spellberg B, Bonomo RA. The deadly impact of extreme drug resistance in Acinetobacter baumannii. Crit Care Med 2014;42:1289-91.

4. Villar M, Cano ME, Gato E, Garnacho-Montero J, Miguel Cisneros J, Ruíz de Alegría C, et al. Epidemiologic and clinical impact of Acinetobacter baumannii colonization and infection: A reappraisal. Medicine (Baltimore) 2014;93:202-10.

5. Garnacho-Montero J, Amaya-Villar R. Multiresistant Acinetobacter baumannii infections: Epidemiology and management. Curr Opin Infect Dis 2010;23:332-9.

6. Montefour K, Frieden J, Hurst S, Helmich C, Headley D, Martin M, et al. Acinetobacter baumannii: An emerging multidrug-resistant pathogen in critical care. Crit Care Nurse 2008;28:15-25.

7. Bayuga S, Zeana C, Sahni J, Della-Latta P, el-Sadr W, Larson E, et al. Prevalence and antimicrobial patterns of Acinetobacter baumannii on hands and nares of hospital personnel and patients: The iceberg phenomenon again. Heart Lung 2002;31:382-90.

8. Gusten WM, Hansen EA, Cunha BA. Acinetobacter baumannii pseudomeningitis. Heart Lung 2002;31:76-8.

9. Choi CH, Lee EY, Lee YC, Park TI, Kim HJ, Hyun SH, et al. Outer membrane protein 38 of acinetobacter baumannii localizes to the mitochondria and induces apoptosis of epithelial cells. Cell Microbiol 2005; 7:1127-38

10. Gaddy JA, Actis LA. Regulation of Acinetobacter baumannii biofilm formation. Future Microbiol 2009;4:273-8

11. Kim SW, Choi CH, Moon DC, Jin JS, Lee JH, Shin JH, et al. Serum resistance of Acinetobacter baumannii through the binding of factor $\mathrm{H}$ to outer membrane proteins. FEMS Microbiol Lett 2009;301:224-31.

12. Jacobs AC, Hood I, Boyd KL, Olson PD, Morrison JM, Carson S, et al. Inactivation of phospholipase D diminishes Acinetobacter baumannii pathogenesis. Infect Immun 2010;78:1952-62.

13. Camarena L, Bruno V, Euskirchen G, Poggio S, Snyder M. Molecular mechanisms of ethanol-induced pathogenesis revealed by RNAsequencing. PLoS Pathog 2010;6:e1000834.

14. Cerqueira GM, Peleg AY. Insights into Acinetobacter baumannii pathogenicity. IUBMB Life 2011;63:1055-60

15. Butt AM, Tahir S, Nasrullah I, Idrees M, Lu J, Tong Y, et al. Mycoplasma genitalium: A comparative genomics study of metabolic pathways for the identification of drug and vaccine targets. Infect Genet Evol 2012;12:53-62.

16. Huynen MA, Diaz-Lazcoz Y, Bork P. Differential genome display. Trends Genet 1997;13:389-90.

17. Huynen M, Dandekar T, Bork P. Differential genome analysis applied to the species-specific features of Helicobacter pylori. FEBS Lett 1998;426:1-5.

18. Zhang R, Lin Y. DEG 5.0, a database of essential genes in both prokaryotes and Eukaryotes. Nucleic Acids Res 2009;37:D455-8.

19. Moriya Y, Itoh M, Okuda S, Yoshizawa AC, Kanehisa M. KAAS: An automatic genome annotation and pathway reconstruction server. Nucleic Acids Res 2007;35:W182-5.

20. Kanehisa M, Furumichi M, Tanabe M, Sato Y, Morishima K. KEGG: New perspectives on genomes, pathways, diseases and drugs. Nucleic Acids Res 2017;45:D353-61.

21. Gardy JL, Spencer C, Wang K, Ester M, Tusnády GE, Simon I, et al. PSORT-B: Improving protein subcellular localization prediction for gram-negative bacteria. Nucleic Acids Res 2003;31:3613-7.

22. Wishart DS, Knox C, Guo AC, Shrivastava S, Hassanali M, Stothard P, et al. DrugBank: A comprehensive resource for in silico drug discovery and exploration. Nucleic Acids Res 2006;34:D668-72.

23. Gaulton A, Bellis LJ, Bento AP, Chambers J, Davies M, Hersey A, et al. ChEMBL: A large-scale bioactivity database for drug discovery. Nucleic Acids Res 2012;40:D1100-7.

24. Bruning JB, Murillo AC, Chacon O, Barletta RG, Sacchettini JC. Structure of the mycobacterium tuberculosis D-alanine: D-alanine ligase, a target of the antituberculosis drug D-cycloserine. Antimicrob Agents Chemother 2011;55:291-301.

25. Kovac A, Majce V, Lenarsic R, Bombek S, Bostock JM, Chopra I, et al. Diazenedicarboxamides as inhibitors of D-alanine-D-alanine ligase
(Ddl). Bioorg Med Chem Lett 2007;17:2047-54.

26. Lacoste AM, Poulsen M, Cassaigne A, Neuzil E. Inhibition of d-alanyld-alanine ligase in different bacterial species by amino phosphonic acids. Curr Microbiol 1979;2:113-7.

27. Woodruff WW $3^{\text {rd }}$, Wolfenden R. Inhibition of ribose-5-phosphate isomerase by 4-phosphoerythronate. J Biol Chem 1979;254:5866-7.

28. Tanaka H, Oiwa R, Matsukura S, Inokoshi J, Omura S. Studies on bacterial cell wall inhibitors. X. Properties of phosph-Nacetylmuramoyl-pentapeptide-transferase in peptidoglycan synthesis of Bacillus megaterium and its inhibition by amphomycin. J Antibiot (Tokyo) 1982;35:1216-21.

29. Brandish PE, Burnham MK, Lonsdale JT, Southgate R, Inukai M, Bugg TD, et al. Slow binding inhibition of phospho-N-acetylmuramylpentapeptide-translocase (Escherichia coli) by mureidomycin A. J Biol Chem 1996;271:7609-14.

30. Gilmour R, Foster JE, Sheng Q, McClain JR, Riley A, Sun PM, et al. New class of competitive inhibitor of bacterial histidine kinases. J Bacteriol 2005; 187:8196-200

31. Zhang J, Zhang L, Li X, Xu W. UDP-3-O-(R-3-hydroxymyristoyl)$\mathrm{N}$-acetylglucosamine deacetylase (LpxC) inhibitors: A new class of antibacterial agents. Curr Med Chem 2012;19:2038-50.

32. Jackman JE, Raetz CR, Fierke CA. UDP-3-O-(R-3-hydroxymyristoyl)$\mathrm{N}$-acetylglucosamine deacetylase of escherichia coli is a zinc metalloenzyme. Biochemistry 1999;38:1902-11.

33. Wu D, Kong Y, Han C, Chen J, Hu L, Jiang H, et al. D-alanine: D-alanine ligase as a new target for the flavonoids quercetin and apigenin. Int $\mathrm{J}$ Antimicrob Agents 2008;32:421-6.

34. Gotoh Y, Eguchi Y, Watanabe T, Okamoto S, Doi A, Utsumi R, et al. Two-component signal transduction as potential drug targets in pathogenic bacteria. Curr Opin Microbiol 2010;13:232-9.

35. Barrett JF, Hoch JA. Two-component signal transduction as a target for microbial anti-infective therapy. Antimicrob Agents Chemother 1998;42:1529-36.

36. Utsumi R, Igarashi, M. Two-component signal transduction as attractive drug targets in pathogenic bacteria. Yakugaku zasshi J Pharm Soc Jpn $2011 ; 132: 51-8$

37. Okada A, Gotoh Y, Watanabe T, Furuta E, Yamamoto K, Utsumi R. [19]-Targeting two-component signal transduction: A novel drug discovery system. Methods Enzymol 2007;422:386-95.

38. Watanabe T, Okada A, Gotoh Y, Utsumi R. Inhibitors targeting twocomponent signal transduction. Adv Exp Med Biol 2008;631:229-36.

39. Tiganova IG, Ilyina TS, Romanova YM. Two-component bacterial regulation systems: Targets of a search for new antibacterial drugs. Mol Genet Microbiol Virol 2014;29:93-103.

40. Stephenson K, Hoch JA. Developing inhibitors to selectively target two-component and phosphorelay signal transduction systems of pathogenic microorganisms. Curr Med Chem 2004;11:765-73.

41. Sass P, Brötz-Oesterhelt H. Bacterial cell division as a target for new antibiotics. Curr Opin Microbiol 2013;16:522-30.

42. den Blaauwen T, Andreu JM, Monasterio O. Bacterial cell division proteins as antibiotic targets. Bioorg Chem 2014;55:27-38.

43. Hong W, Xie J. Progress of ftsZ inhibitors as novel antibiotics leads. Crit Rev Eukaryot Gene Expr 2013;23:327-38.

44. Chan FY, Sun N, Neves MA, Lam PC, Chung WH, Wong LK, et al. Identification of a new class of ftsZ inhibitors by structure-based design and in vitro screening. J Chem Inf Model 2013;53:2131-40.

45. Stokes NR, Baker N, Bennett JM, Berry J, Collins I, Czaplewski LG, et al. An improved small-molecule inhibitor of ftsZ with superior in vitro potency, drug-like properties, and in vivo efficacy. Antimicrob Agents Chemother 2013;57:317-25.

46. Domadia P, Swarup S, Bhunia A, Sivaraman J, Dasgupta D. Inhibition of bacterial cell division protein ftsZ by cinnamaldehyde. Biochem Pharmacol 2007;74:831-40.

47. Sun N, Chan FY, Lu YJ, Neves MA, Lui HK, Wang Y, et al. Rational design of berberine-based ftsZ inhibitors with broad-spectrum antibacterial activity. PLoS One 2014;9:e97514

48. Bigham EC, Gragg CE, Hall WR, Kelsey JE, Mallory WR, Richardson DC, et al. Inhibition of arabinose 5-phosphate isomerase. An approach to the inhibition of bacterial lipopolysaccharide biosynthesis. J Med Chem 1984;27:717-26.

49. Airoldi C, Sommaruga S, Merlo S, Sperandeo P, Cipolla L, Polissi A, et al. Targeting bacterial membranes: NMR spectroscopy characterization of substrate recognition and binding requirements of D-arabinose-5-phosphate isomerase. Chemistry 2010;16:1897-902.

50. Gourlay LJ, Sommaruga S, Nardini M, Sperandeo P, Dehò G, Polissi A, et al. Probing the active site of the sugar isomerase domain from $E$. Coli arabinose-5-phosphate isomerase via X-ray crystallography. Protein Sci 
2010;19:2430-9.

51. De Leon GP, Elowe NH, Koteva KP, Valvano MA, Wright GD. An in vitro screen of bacterial lipopolysaccharide biosynthetic enzymes identifies an inhibitor of ADP-heptose biosynthesis. Chem Biol 2006; $13: 437-41$

52. Bugg TD, Lloyd AJ, Roper DI. Phospho-murNAc-pentapeptide translocase (MraY) as a target for antibacterial agents and antibacterial proteins. Infect Disord Drug Targets 2006;6:85-106.

53. Ha S, Gross B, Walker S. E. Coli murG: A paradigm for a superfamily of glycosyltransferases. Curr Drug Targets Infect Disord 2001;1:201-13.

54. Ezhilarasan V, Sharma OP, Pan A. In silico identification of potential drug targets in Clostridium difficile R20291: Modeling and virtual screening analysis of a candidate enzyme MurG. Med Chem Res 2013;22:2692-705.

55. Tripathi P, Tripathi V. Determination of murG transferase as a potential drug target in Neisseria meningitides by spectral graph theory approach. In: Perspectives in Environmental Toxicology. Cham: Springer International Publishing; 2017. p. 147-60

56. Dineshkumar B, Vigneshkumar P, Bhuvaneshwaran SP, Mitra A. Advanced drug designing softwares and their applications in medical research. Int J Pharm Pharm Sci 2010;2:16-8. 